\title{
Magnesium and parathyroid hormone among end-stage renal disease patients
}

\author{
Seyed Seifollah Beladi Mousavi, Fatemeh Hayati, Shokouh Shayanpour, Shahla Ahmadi Halili*
}

\section{Dear Editor}

With great interest, we read the recently published article entitled "serum magnesium in association with parathyroid hormone levels in routine hemodialysis patients" by Fooladgar and colleagues in Journal Parathyroid Disease (1).

They evaluated, in a cross-sectional study, the serum levels of magnesium $(\mathrm{Mg})$, calcium, phosphorus and intact PTH (iPTH) among 56 end-stage renal disease (ESRD) patients undergoing maintenance hemodialysis (HD) in a $\mathrm{HD}$ center (1).

The results of the study showed a significantly positive correlation between iPTH and serum Mg levels among these patients (1).

Hypermagnesemia is an uncommon laboratory finding among healthy adults and symptomatic hypermagnesemia is a rare disorder among patients with normal renal function, because the normal kidney is able to rapidly excrete magnesium loading by reducing magnesium tubular reabsorption $(2,3)$.

Hypermagnesemia is also not a prominent feature among patients with chronic kidney disease (CKD), in the absence of increased magnesium administration, however renal failure mostly at its final stages is most common cause of hypermagnesemia (4).

The relationship between iPTH and serum Mg levels in healthy adults and CKD patients, the effect of hypermagnesemia on disorders of mineral and bone metabolism, and the effect of chronic hypermagnesemia on PTH levels among ESRD patients as evaluated by Fooladgar et al are important issues (1,4-7).

It is suggested that, hypermagnesemia can inhibit the secretion of PTH among patients with normal renal function and it usually causes transient and asymptomatic hypocalcemia by this mechanism $(2,3)$.

This effect has been described in some studies which have showed that acute intravenous administration of magnesium sulfate decreases PTH secretion and corrected serum calcium level in healthy person and in pregnant women with eclampsia (2).

In contrast to normal person, the effect of chronic

\author{
Implication for health policy/practice/research/medical \\ education \\ Hypermagnesemia is also not a prominent feature among \\ patients with chronic kidney disease, in the absence of \\ increased magnesium administration, however renal \\ failure mostly at its final stages is most common cause of \\ hypermagnesemia. \\ Keywords: Magnesium, Parathyroid hormone, Chronic \\ kidney disease, End-stage renal disease
}

hypermagnesemia on PTH levels among ESRD patients is not well investigated, while studies regarding this issue was existed. Some of these investigations have also methodological limitations. In addition, the results of these studies are also conflicting $(8,9)$.

The results of the study by Fooladgar et al showed a positive relationship between iPTH and serum Mg levels among HD patients, however most of other studies in HD patients and also most of studies among ESRD patients undergoing peritoneal dialysis showed a significant inverse relationship between serum $\mathrm{Mg}$ and serum intact PTH levels $(1,8,9)$.

Therefore, as Fooladgar et al recommended, there still remains a number of big questions about this issue and it is necessary to further evaluate of role of $\mathrm{Mg}$ in secondary hyperparathyroidism and vascular calcification. Therefore, further clinical studies and multi-centric investigation are necessary (1).

\section{Authors' contribution}

SAH and FH prepared the primary draft. SBM prepared the final paper. All authors read and signed the edited manuscript.

\section{Conflicts of interest}

The authors declare that, they have no conflict of interests.

Ethical considerations

Ethical issues (including plagiarism, data fabrication, double publication) have been completely observed by the 
authors.

\section{Funding/Support}

None.

\section{References}

1. Fooladgar M, Malekpour A, Asgari-Savadjani S, Mardani S. Serum magnesium in association with parathyroid hormone levels in routine hemodialysis patients. J Parathyr Dis. 2018;6:13-15. doi: 10.15171/jpd.2018.05.

2. Quamme GA. Control of magnesium transport in the thick ascending limb. Am J Physiol. 1989. 256:F197-210.

3. Musso CG. Magnesium metabolism in health and disease. Int Urol Nephrol. 2009;41:357-62. doi: 10.1007/s11255009-9548-7.

4. Moe SM, Drüeke T, Lameire N, Eknoyan G. Chronic kidney disease-mineral-bone disorder: a new paradigm. Adv Chronic Kidney Dis. 2007;14:3-12.

5. Beladi Mousavi SS, Alemzadeh Ansari MJ, Cheraghian B.
Outcome of Patients on Hemodialysis in Khuzestan, Iran. NDT plus 2011;4:143-144.

6. Beladi Mousavi SS, Soleimani A, Beladi Mousavi M. Epidemiology of end-stage renal disease in Iran: a review article. Saudi J Kidney Dis Transpl. 2014;25:697-702.

7. Beladi Mousavi SS, Alemzadeh-Ansari MJ, AlemzadehAnsari MH. Long-term survival of patients with end-stage renal disease on maintenance hemodialysis: a multicenter study in Iran. Iran J Kidney Dis. 2012;6:452-6.

8. Navarro JF, Mora C, Jiménez A, Torres A, Macía M, García J. Relationship between serum magnesium and parathyroid hormone levels in hemodialysis patients. Am J Kidney Dis. 1999;34:43-8.

9. Cho MS, Lee KS, Lee YK, Ma SK, Ko JH, Kim SW, et al. Relationship between the serum parathyroid hormone and magnesium levels in continuous ambulatory peritoneal dialysis CAPD patients using low-magnesium peritoneal dialysate. Korean J Intern Med. 2002;17:114-21.

Please cite this paper as: Beladi Mousavi SS, Hayati F, Shayanpour S, Ahmadi Halili S. Magnesium and parathyroid hormone among end-stage renal disease patients. J Parathyr Dis. 2018;6(2):72-73. doi: 10.15171/jpd.2018.22.

Copyright () 2018 The Author(s); Published by Nickan Research Institute. This is an open-access article distributed under the terms of the Creative Commons Attribution License (http://creativecommons.org/licenses/by/4.0), which permits unrestricted use, distribution, and reproduction in any medium, provided the original work is properly cited. 